\title{
Stefan KIEDROŃ
}

ORCID: 0000-0002-3564-7053

Uniwersytet Wrocławski

\section{"Getrouwste hofstijl der Sarmaeten...". Joost van den Vondel en Jan Andrzej Morsztyn over poëzie en politiek}

\begin{abstract}
This article presents two 17th-century poets, Joost van den Vondel and Jan Andrzej Morsztyn, against the backgrounds of the Dutch and the Polish Golden Age. They were 'connected' in their times: both through poetry and politics. Vondel's Parnaes aen de Belt (1657) included a poem for Tobiasz, the brother of the Polish poet, in which he was praised as the "Getrouwste hofstijl der Sarmaeten" (Most fidel court pillar of the Sarmatians); and also Jan Andrzej received praise here. In his other poems, Vondel had written about the greatness of the Polish-Lithuanian Commonwealth, among other things about the city of Danzig (Polish: Gdańsk), which he, in his ode "Bestand tusschen Polen en Zweden. Aen Dantzik"; (Truce between Poland and Sweden. For Danzig"; 1635), called the "Parrel aen de Kroon van Polen" (Pearl at the Crown of Poland).

On the other hand, the Morsztyn brothers were interested in the developments of the Republic of the United Provinces. Like many other foreigners, they undertook a Peregrinatio Academica to Leiden where they could see the prosperity of the Republic at first hand, together with other Poles (including the poet-preacher Samuel Przypkowski, the poet-preacher Andrzej Węgierski or the later secretary of the Polish King Andrzej Rej). This Polish circle in the Republic is also shown here.

However, there is a double meaning to be discovered in the connection 'Morsztyn-Vondel': there was more politics in it than poetry. Morsztyn's perspective was mainly directed to France (even against the Polish king) — and Vondel's perspective not to Poland as a political power, but to the Dutch 'Moedernegotie' (Mother of all trades) in the Baltic Sea, between the Danish Sound and Danzig. This double meaning is also shown here.
\end{abstract}

Keywords: Joost van den Vondel, Jan Andrzej Morsztyn, Tobiasz Morsztyn, Golden Age, Republic of the United Provinces, Polish-Lithuanian Commonwealth, Moedernegotie. 


\section{Dichters van de Gouden Eeuw?}

Joost van den Vondel en Jan Andrzej Morsztyn waren allebei in de $17^{\text {de }}$ eeuw dichterlijk actief. Zij worden in de respectievelijke literatuurgeschiedenissen, de Nederlandse en de Poolse, vandaag als de 'iconische' poëticale vertegenwoordigers van hun tijd gezien (Porteman, Smidts-Veldt 2008: 21, "Vondel [...] de meest bewonderde tragedieschrijver en lyrisch dichter"; Hernas 1999: 294, "Jan Andrzej Morsztyn - Mistrz Barokowy" [Jan Andrzej Morsztyn - Barokke Meester]).

Vondel was dus de meesterdichter van een tijdperk dat algemeen als 'de Gouden Eeuw' (in het Latijn Aurea Aetas, maar ook Auraeum Saeculum genoemd) wordt gezien (zie bijv. Schama 1987; Schama 1989). Daarbij duurde (en duurt) een gouden eeuw nooit 100 jaar; de Nederlandse ook niet. Deze wordt in de moderne geschiedschrijving weliswaar in (soms zeer) brede tijdgrenzen gezet (Israel 1995 verdeelt hem in de vroege, 1588-1647, en de late, 1647-1702, Gouden Eeuw). Het is echter misschien ook mogelijk om de tijdgrenzen ervan te bepalen met enerzijds 1602 (oprichting van de VOC), eventueel 1609 (Twaalfjarig Bestand) en anderzijds 1672 (Rampjaar). De Vrede van Munster in 1648 lijkt de 'top' te zijn; de jaren ' 50 (vanaf Cromwells Navigation Act in 1651) en ' 60 brachten niet meer zo'n bloei met zich mee, en het Rampjaar luidde het einde ervan in.

De tijdsbenaming is begrijpelijk: de Noordelijke Nederlanden beleefden toen op economisch en politiek vlak, en vervolgens ook op cultureel en literair vlak, een voordien ongekende bloei. De veelvuldige rijkdom van de nieuwe staat wekte bewondering in heel Europa; ook in Polen.

En de Poolse Gouden Eeuw? Is dit ook de $17^{\text {de }}$ eeuw? Kan Morsztyn een "dichter van de Poolse Gouden Eeuw" genoemd worden? Nee, de Poolse 'Gouden Eeuw' wordt in de moderne historiografie geplaatst in de $16^{\text {de }}$ eeuw. Toen was het Pools-Litouwse Gemenebest een van de machtigste landen van Europa (zie o.a. Vos \& Goddeeris 2005). In deze tijd kende het land op politiek en economisch vlak een grote bloei. En ook de Poolse (Renaissance)poëzie beleefde, met Mikołaj Rej en (vooral) Jan Kochanowski, een vroeger ongeziene bloei.

De Poolse $17^{\text {de }}$ eeuw wordt anders genoemd: "de Zilveren Eeuw" (zie Jasienica 2018). De eerste decennia van die eeuw waren trouwens, politiek en economisch gezien, geenszins een slechte tijd voor het land. Het was niet direct verwikkeld in de Dertigjarige Oorlog, en in de oorlogen tegen Rusland was het vrij succesvol: in 1635, onder koning Wladislaus IV, bereikte het zijn grootste omvang, bijna 1 miljoen $\mathrm{km}^{2}$. Pas met de dood van die koning in 1648 eindigde deze goede tijd en begon een tijd van politiek en economisch verval onder Jan II Casimir Wasa. Aangevallen door eerst de Kozakken, daarna Rusland en tenslotte Zweden ('De Zweedse Zondvloed' 1655-1660), verarmde zijn koninkrijk zodanig dat hijzelf in 1668 troonsafstand deed en naar Frankrijk emigreerde, waar hij eind 1672 overleed. 
Dit zijn karakteristieke jaartallen voor Nederland én voor Polen.

De 'Gouden Eeuw' vond bij Vondel een duidelijke uitdrukking. Toen hij ter gelegenheid van de stichting van het Amsterdamse Athenaeum Illustre in 1632 de ode Inwying der doorluchtige Schoole t'Amsterdam schreef, noemde hij daarin "De Poësy, het Goddelijckst van al" (WB III: 375). En die poëzie verbond hij met de woorden "O goude lettereeuw!" (WB III: 375). Niet lang daarna, in 1638, kwam Morsztyn naar Holland. En een kwarteeuw later, in 1657, schreef Vondel over hem en over zijn broer Tobiasz een gedicht in de bundel Parnaes aen de Belt.

Op die manier kruisden de wegen van de twee dichters, tenminste indirect. Maar het was niet de poëzie die de twee dichters toen had verbonden, of niet alleen. De politiek en de economie namen hier de eerste plaats in.

\section{De Republiek der Zeven Verenigde Nederlanden en De Republiek der Twee Naties}

Daarom nu iets meer over de politiek. Er viel hier reeds de benaming 'Pools-Litouws Gemenebest'. Een doorsnee Nederlander weet met deze naam niet veel te beginnen. Anderzijds weet een doorsnee Pool misschien ook niet veel te beginnen met de naam 'Republiek der Zeven Verenigde Nederlanden'...

Later werd nog een andere naam voor de in 1569 gestichte federatie van de Kroon Polen en het Groothertogdom Litouwen gebruikt: 'Rzeczpospolita Obojga Narodów'. Dit wordt meestal vertaald als 'Republiek van de Twee Naties'. Het was echter geen republiek in de huidige zin, maar een Commonwealth.

De grenzen ervan strekten zich in deze tijd uit van de Oostzee tot Smolensk en van Dorpat (vandaag Tartu) tot bijna naar het Zwarte Meer (zie o.a. Stone 2014; Norkus 2017). En de Republiek kende verschillende religies. De staatsreligie was het rooms-katholicisme, daarnaast was ook het orthodoxe geloof sterk. Het protestantisme had ook veel invloed. Polen wordt vandaag geasoccieerd met het katholicisme, maar in de $16^{\text {de }}$ en $17^{\text {de }}$ eeuw waren de lutheranen, de calvinisten en ook de socinianen invloedrijke groeperingen in Polen en in Litouwen (zie daarover o.a. Tazbir 1973, Wilczek 2016).

Eigenlijk moesten het drie naties zijn, met de Ruthenen (de huidige Oekraïners) erbij; maar dat hebben de Polen niet geaccepteerd. Zij, de Polen, hadden de bovenhand gekregen in het nieuwe staatsbestel. De Litouwers kregen niet zo veel invloed als ze wilden, en de Ruthenen nog veel minder. Deze politieke beslissing had ook een grote invloed uitgeoefend op de culturele en literaire wereld in het Gemenebest; Pools domineerde in de hele staat.

Net als Polen was de Republiek der Verenigde Provinciën officieel een federatie, met zeven autonome provincies (plus Drenthe erbij). In Europa sprak men 
echter algemeen (en spreekt men vaak tot vandaag) over deze staat als 'Holland' (en vaak over de 'Hollandse', niet Nederlandse taal), want deze provincie was de belangrijkste. Net als in Polen waren er in de Republiek meerdere religies, maar één daarvan had een politiek overgewicht: het calvinisme.

En er was nog iets: mythes die voor de beide staten vormend waren. De Republiek had de mythe van de Bataven (poëtisch door Pieter Corneliszoon Hooft in zijn Baeto verwoord, historiografisch door Hugo Grotius in zijn De antiquitate Reipublice Batavicae), de Rzeczpospolita had de mythe van de Sarmaten (zie bijv. de gedichten van Wacław Potocki). In de eerste helft van de $17^{\text {de }}$ eeuw behoorden de Bataven en de Sarmaten tot de machtigste volkeren in Europa.

\section{Naar Holland!}

In de eerste helft van de $17^{\text {de }}$ eeuw, vooral in het derde, vierde en vijfde decennium ervan, kwamen heel veel buitenlanders naar de Republiek, of gewoonweg: naar Holland. Veel van hen kwamen hier om economische redenen, voor zaken, velen kwamen wegens de religieuze vrijheid voor de protestanten, velen kwamen om aan de snel beroemd geworden Leidse universiteit te studeren (zie De Rieu 1875).

In de kwarteeuw 1625-1650 werd deze universiteit zeer 'internationaal'. In die tijd studeerden hier soms meer buitenlanders dan Nederlanders (Colenbrander 1925: 278; Wansink 1981: 7-10). Ze wilden tijdens de door hen geabsolveerde Grand Tour dit "Bolwerk van de vrijheid" (Otterspeer 2000) zien. En al was deze Peregrinatio Academica, 'academische pelgrimage', een "fast-food technology of university education" (zo Borowski 2007: 106) voor de vermogende jeugd van deze tijd in heel Europa, de 'Peregrinatores' hadden hun Hollandse bestemming zeer doelbewust gekozen. Zeker was een van de redenen daarvoor ook het feit dat in heel Europa de Dertigjarige Oorlog met al zijn wreedheden woedde. En in Holland kon men, naast de oorlog tegen Spanje, ook wel rustig handel in specerijen uit Oost-Indië drijven en tulpen kweken...

In betrekkelijk korte tijd ontstonden in de Republiek vijf universiteiten: naast Leiden (vanaf 1575) ook in Franeker (1585), Groningen (1614), Utrecht (1636) en Harderwijk (1648); in Amsterdam onstond ook het reeds eerder genoemde Athenaeum Illustre, een semi-universiteit als tegenhanger van Leiden (1632). Dat was voor zo'n klein gebied heel veel. Het Pools-Litouwse Gemenebest had er, met zijn oppervlakte van ca. 1 miljoen $\mathrm{km}^{2}$ en ca. 11 miljoen inwoners, slechts twee: één voor Polen in Kraków en één voor Litouwen in Vilnius (een derde universiteit was er nog in het Hertoglijk Pruisen, in Königsberg, waar de Poolse koning leenheer van was).

De Grand Tour leidde van universiteit tot universiteit, ook binnen de Republiek. Sommige van de studenten konden kort na aankomst hun dissertaties voor- 
leggen of werden in zeer korte tijd zelfs professoren (een spectaculair voorbeeld was de Pool Jan Makowski die in oktober 1613 naar Franeker kwam, hier in maart 1614 zijn proefschrift verdedigde, in januari 1615 Extraordinarius in de theologie werd, in juni 1615 Ordinarius en in december 1615 Rector Magnificus; zie over hem o.a. Kuiper Jr. 1899; Tazbir 1974: 240-241).

Een van de Leidse studenten was Jan Andrzej Morsztyn, die hier in juli 1638 aankwam. Hij was niet de enige Pool in Leiden; ook niet de eerste. Er kwamen reeds Polen naar Leiden aan het einde van de $16^{\text {de }}$ eeuw (Kiedroń 1992: 194). In de genoemde meest 'internationale' kwarteeuw kwamen hier honderden studenten uit het Poolse-Litouwse Gemenebest. Enkele belangrijke namen worden hier genoemd.

In november 1616 kwam er een groep van acht Poolse edellieden, allemaal protestanten. Onder hen was een (verder niet zo bekende) Jan Morsztyn, en ook Samuel Przypkowski, zoon van de senior van de antitrinitaristische, Sociniaanse gemeente in Lusławice, ten oosten van Kraków, later een belangrijke theoloog en dichter, auteur van o.a. de Dissertatio de pace et concordia ecclesiae (Dissertatie over de vrede en eendracht in de kerk, Amsterdam 1628).

In 1627 kwam Andreas Vengertius Polonus (Andrzej Węgierski, 1600-1649), voor de studie van godgeleerdheid. Hij was calvinist met een protestants-oecumenische houding; hij wilde het calvinisme met Comenius' Tsjechische Broeders verenigen. Na zijn terugkomst uit Leiden had hij diens Janua linguarum reserata (De talenpoort geopend, 1631) in het Pools vertaald; hij werd ook rector van het gymnasium van de Tsjechische Broeders in Leszno, waar hij met Comenius samenwerkte. Zijn geschiedenis van de reformatie in de Slavische landen verscheen postuum, eerst anoniem en later onder zijn naam in 1679 in Amsterdam. Hij was ook dichter, o.a. auteur van bruiloftsgedichten.

Enkele maanden voor Morsztyn kwam Andrzej Rej (kleinzoon van de eerste moderne Poolse dichter Mikołaj Rej), latere secretaris van koning Wladislaus IV. Bijna 40 jaar later kwam hij tijdens een diplomatieke reis opnieuw naar de Nederlanden. Het verhaal gaat dat hij toen bij Rembrandt een portret had besteld dat vandaag onder de titel 'Poolse Edelman' in de National Gallery of Art in Washington te vinden is (Odlozilik 1963).

Aan het einde van dit 'internationale' decennium, in 1649, werd als studiosus politices Stanisław Lubieniecki ingeschreven, later een van de belangrijkste Poolse polyhistoren. Ook hij stond, net als Radziwiłł, in de Zweeds-Poolse oorlog aan de kant van de Zweden, hopende dat koning Karel X Gustaaf de rechten van de Poolse protestanten terug zou brengen. 


\section{Jan Andrzej Morsztyn in Leiden}

In deze protestantse kringen, onder deze internationale groep studenten, verbleef Morsztyn vanaf de zomer 1638. Hij werd officieel op 23 juli ingeschreven, als Andreas Morst Polonus, 18 jaar oud, letterenstudent. Samen met hem werd Martinus Plor ingeschreven, waarschijnlijk zijn gouverneur, want hij was tien jaar ouder dan Morsztyn; en hij studeerde theologie.

Voor Morsztyn was dit een onderdeel van zijn Grand Tour, die hem later naar Frankrijk en Italië leidde. Uit een familie uit de kring van de Poolse Broeders (de Poolse Socinianen, ook Arianen genoemd) stammend, maakte hij in latere jaren wel een grote politieke carrière aan het hof van de Poolse (katholieke) koning Jan II Casimir, eerst als koninklijke secretaris, later als thesaurier van de Kroon (dus van het Poolse deel van het Gemenebest). Dat een protestant in de tijd van de 'Zweedse Zondvloed' zo'n carrière in Polen kon maken, is eenvoudig te verklaren: Morsztyn verliet zijn vroegere religie en werd katholiek. Noodlottig werd hem zijn pro-Franse houding na de troonsafstand van Jan Casimir (zie daarover o.a. Van der Mandere 1920). Toen zijn complot tegen de volgende Poolse koning Jan III Sobieski, in samensprak met Louis XIV, werd ontdekt, ging hij in 1683 als emigrant naar Parijs. Hier werd hij secretaris van de Franse koning en hier stierf hij, als 'verrader van Polen'. En toch was het Morsztyn die (veel later) in de Poolse literatuurgeschiedenis over de $17 \mathrm{de}$ eeuw het meest beroemd zou worden. Als dichter, want zo ging hij de Poolse geschiedenis in.

De jonge Poolse Sociniaan kwam naar Holland, als Peregrinus Academicus, in het jaar van de grootste internationale bloei van de Leidse universiteit. Deze academische en internationale sfeer had ook op Morsztyn een sterke invloed uitgeoefend. En ook zijn poëticale activiteiten begonnen hier in Leiden. De eerste gedichten van de jonge Pool, die vanaf 1638 ontstonden, werden door hem, samen met zijn latere gedichten, in de bundel onder de titel Lutnia (De Luit, onder inspiratie van Giambattista Marinis La Lira) verzameld. Een latere dichtbundel heette Kanikuła albo Psia gwiazda (Canicula of Hondsster). Morsztyn had ook een deel van Marinis Adone en Torquatto Tasso's Aminta vertaald, en ook - dit was zijn belangrijkste vertaalwerk - Le Cid van Pierre Corneille. Bij die laatste vertaling had hij waarschijnlijk gebruik gemaakt van een Leidse uitgave in het Frans; het officiele uitgavejaar was 1638, maar feitelijk verscheen deze druk ná 1644 (zo Karpiński \& Stepnowski 1999: 111-112).

Morsztyns verblijf in Leiden had ook andere leden van zijn familie geïnspireerd om deze Hollandse universiteit in het programma van hun Peregrinatio Academica op te nemen. Een jaar na Jan Andrzej hadden zich zijn broers Stanislaus Morstyn Nobilis Polonus, 17 jaar oud, en Tobias Morstyn, ejus frater, 15 jaar oud, voor de letterenstudie ingeschreven. Zij verbleven een langere tijd in Holland, of zij kwamen na enkele jaren terug: in februari 1645 werden ze 
namelijk allebei opnieuw ingeschreven. Stanisław werd later, net als Jan Andrzej, ook dichter. Hij heeft o.a. Phaedra van Seneca en Andromaque van Jean Racine vertaald; hij was ook auteur van een serie gelegenheidsgedichten. Tobiasz werd geen dichter, maar maakte ook carrière aan het Poolse hof. Ook hij werd namelijk, net als zijn oudere broer, katholiek en werd na zijn overgang een belangrijke ambtenaar bij koning Jan II Casimir.

Hij werd bovendien bezongen in een gedicht van Vondel.

\section{Naar Polen?}

Heel anders was het met de andere richting gesteld, namelijk vanuit Nederland naar Polen. Wel was dit land in de $16^{\text {de }}$ en vroege $17^{\text {de }}$ eeuw, zoals gezegd, een Europese mogenheid in politiek opzicht, maar in cultureel en maatschappelijk opzicht speelde het een veel geringere rol.

Er was echter één uitzondering: de handel. De Republiek der Verenigde Nederlanden was zéér geïnteresseerd in commerciële contacten met de Republiek der Twee Naties. Eigenlijk ging het alleen om handelscontacten met één stad: Dantzig (Pools: Gdańsk). Deze stad aan de Oostzee was de "Parrel aen de kroon van Polen". Zo schreef Vondel in 1635 in zijn ode "Bestand tusschen Polen en Zweden. Aen Dantzik":

Schoone Star van 't vruchtbre Pruissen,

Koningin van 't Noordsch gewest,

Die de sevenstarre lest [...].

Parrel aen de kroon van Polen,

Die ghy eert in soet en suur:

Bijkorf, groote korenschuur,

Wie de nooddruft is bevolen

Van soo menigh land en Rijck:

Veler menschen burg en wijck [...] (WB III, 1929: 428).

De beginwoorden zijn een parafrase van de Poolse jezuïet, een in heel Europa beroemd Neolatijns dichter, Horatius Christianus (Hernas 1999: 249), Maciej Kazimierz Sarbiewski. Vondel was niet de eerste die deze Poolse dichter parafraseerde of vertaalde; een van die eerdere vertalers was Hooft. Hij had Sarbiewskis tweede ode "Ad Aurelium Lycum" uit het eerste boek van diens Lyricorum Libri $I V$ vertaald (in 1632, en opnieuw in 1634, in Antwerpen bij Officina Plantiniana uitgegeven, met het frontispice door niemand minder dan Rubens ontworpen), als "Troost in wederspoedt. Aen eenen vriendt", en in een brief van december 1634 uit Brussel aan zijn zwager Justus Baak gestuurd (Borowski 2007: 148). 
Vondels parafrase stamde van het begin van de achtste ode "Laus Dantisci" van Sarbiewski. Deze "Laus" begint met de woorden "O sidus Borussae Gentis Hyperboreique late Regina Coeli" (Hulsenboom 2019: 98).

Inderdaad: Dantzig was de economisch en soms ook politiek belangrijkste, en rijkste, stad van het Koninkrijk Polen. Dantzig was 'een klein Nederland'; Hollanders die naar hier kwamen waanden zich 'in Amsterdam te zijn'. De stad kreeg dus lof van Vondel. En ook de Poolse koning Wladislaus IV kreeg lof. Deze had vroeger met groot succes tegen de Turken gevochten en had nu een bestand met Zweden getekend, en was volgens Vondel als dé triomfator uit de onderhandelingen gekomen:

$\mathrm{Nu}$ en is 't geen minder zege,

Dat hy binnen syn paleis

Kust dien vorderlijcken pais (WB III, 1929: 429).

Dit waren zeer lovende woorden, maar de intentie van Vondel was niet om de Poolse koning te verheerlijken. Hij prees het einde van het Pools-Zweedse conflict, want op die manier was de weg van Dantzig via de Deense Sont naar Amsterdam (weer) vrij. Vrij voor de 'Moedernegotie': de handel met graan uit Polen, want dat had Nederland broodnodig. Hij onderstreepte dat:

$\mathrm{Nu}$ en hoeftghe niet te duchten

Dat de kleppers sonder tal

Gaen vertrapplen over al

Ceres oegst en goude vruchten:

Datmen alles hang en waegh

Aen een droeve nederlaegh.

' $\mathrm{k}$ Sie den Wyssel uit sijn kaenen [=schuiten]

Schudden sonder tegenstoot

In uw' opgedaenen schoot

Maght van opgeleide graenen (WB III, 1929: 429).

Vondel kwam enkele keren terug op deze kwestie. Toen in 1645 Maria Ludovica Gonzaga uit Parijs via Amsterdam naar Warschau ging om de Poolse koning te trouwen, schreef hij het gedicht "Geluck aen Louyze Marie, Koningin van Polen en Sweden", waar hij het wapen van de nieuwe koningin, de fleur-de-lis, met de Wijssel en de oogst van de akkerlieden daar (graan dus) poëticaal had verbonden:

Terwijl de Wijssel, rijck van granen,

Voortaen den Aemstel voller kaenen

Belooft en toegiet, op dees trouw:

Waer d'ackerlieden in den bouw

De Lelien in 't koren pluicken (WB V, 1931: 147). 
Hij sloot zijn gedicht af met de woorden "Nu Dantzigk feest houdt met Parijs" (WB V, 1931: 147). Niet Warschau houdt feest, nee, wel Dantzig. Deze stad is de belangrijkste vanwege de strategische ligging in de graanhandel. En ook later zou Vondel de "Vrye zeevaart naar Oosten", dus naar Dantzig, prijzen, toen in 1658 admiraal Jacob van Wassenaer Obdam de Sont 'openmaakte' voor de 'Moedernegotie'.

Het belang van de graanhandel met Polen onderstreepte later ook de rijke koopman uit Leiden Pieter de la Court, dezelfde die in de jaren 30 samen met Morsztyn studeerde, in zijn traktaat Interest van Holland, ofte gronden van Hollands-Welvaren uit 1662. Hij schreef over handelscontacten, vanaf de Middeleeuwen, met "het vette Pruissen en Lijfland, en de rivieren Weissel, Pregel, en Duin", waarlangs

alles uit Poolen, Littauwen, ofte Rusland in zee moet daalen: by welke gelegentheid de naast aan zee geleegen Oosterse steeden hebben begonnen die groove waren te haalen, en naa de Neederlanden, Engeland en Vrankrijk te voeren, alsmede daar van daan heen en weeder te brengen, alle overvloed en gebrek (De la Court 1662: 26-27).

En bijna een decennium later schreef Joannes Antonides van der Goes in het tweede boek van zijn Ystroom uit 1671 in dezelfde geest:

Het vruchtbre Pruissen schenkt in volgeladen Kaenen

Voor overvloet van gelt een rijken schat van graenen [...] (Van der Goes 1671: 62).

De woorden van Pieter de la Court over "het vette Pruissen" en over de rivier "Wijssel", en de woorden van Van der Goes over "het vruchtbre Pruissen" klinken als een echo van Vondel. Het lofdicht voor Wladislaus IV begon zo, en ook in de Gysbreght van Aemstel lezen wij (in het vijfde bedrijf):

schep moed, en wanhoop niet,

[Gods] wil is, dat ghy treckt na'et vette land van Pruissen,

Daer uit het Poolsch geberght de Wijsselstroom koomt ruisschen

Die d'oevers rijck van vrucht genoeghelijck bespoelt.

Verhou u daer, en wacht tot dat de wraeck verkoelt.

Ghy zult in dit gewest een stad, Nieuw Holland, bouwen,

En in gezonde lucht, en weelige landouwen,

Vergeten al uw leet, en overbrogten druck;

Waer door uw naezaet klimt den bergh op van 't geluck (WB III, 1929: 598).

Vondel kon hier trouwens alweer inspiratie bij Sarbiewski hebben gevonden, toen hij over de vruchtrijke Wijsseloevers schreef; in zijn ode "Laus Dantisci" schreef de Poolse dichter over "vitrei super sedisse felix margine Vistulae...".

Zelfs meer dan honderd jaar later, in 1793, aan het einde van het Pools-Litouwse Gemenebest (en van de Republiek) schreef predikant-historicus Willem Albert Bachiene in zijn Beknopte beschryving [...] der Zeven Vereenigde Nederlanden dat deze landen 
geen gebrek [hebben] aan veelderhande soort van de smaaklykste boomvrugten. Doch zy leveren niet zo veel voorraad van Koorn uit als de ingezetenen van nooden hebben, want schoon dit wel in eenige Provincien, als Gelderland, Zeeland, Brabant, Vlaanderen en Artois zeer weelderig groeit, zo kan dit egter niet toereiken, om de behoeftens van zoo veele inwooners, ook van de andere Provincien, te vervullen, waarom 't Koorn dan ook Jaarlyks uit Lyfland, Koerland, Pruissen en Poolen, over de Oost-Zee moet worden aangevoerd (Bachiene 1793: 5).

\section{Vondel over Morsztyn}

Wat kon Vondel over Jan Andrzej Morsztyn weten? Niets, of: niet veel... De werken van de Poolse dichter werden tijdens zijn leven niet uitgegeven; wel circuleerden ze in handschriften en in afschriften. Zijn vertalingen van Corneille, Marini en Tasso verschenen (door toedoen van zijn broer Stanisław) pas enkele jaren na zijn dood in druk; en de dichtbundels Lutnia en Kanikuta albo Psia Gwiazda werden pas in de $19^{\text {de }}$ eeuw uitgegeven. Dankzij die late uitgaven wordt hij vandaag als een van de belangrijkste Poolse dichters van de $17^{\text {de }}$ eeuw gezien.

Er werd vaak de vraag gesteld waarom hij zijn gedichten niet publiceerde. Wel had hij dat overwogen: in Lutnia had hij een van zijn gedichten "Do swoich książek" (Aan zijne boeken) gericht (zie Hernas 1999: 302):

Dokąd się, moja Lutni, napierasz skwapliwie?

Chcesz na świat i drukarskiej chciałabyś oliwie

Podać w nielutościwe swoje plotki prasy,

Wzgardziwszy słodkie mego kabinetu wczasy?

Waar dring' je toch zo driftig aan, mijn Luit, en perse?

Aan de wereld, door meedogenloze drukkersperse

En diens olie, mijn vluchtige verzinsels geven,

En ver van zoete rust mijns kabinets te leven? (vert. SK)

Misschien was Morsztyns beslissing om zijn gedichten niet te publiceren verbonden met zijn streven naar perfectie. Maar er was nog iets: de steeds strenger wordende politieke, religieuze en zedelijke censuur hield hem van een publicatie af; hij gold bij sommigen als een immorele dichter (zie Hernas 1999: 302).

Helemaal anders was het met de werken van Vondel. Ze verschenen reeds bij zijn leven allemaal in druk (ook al had de katholieke Vondel soms problemen). De verklaring voor die rijkdom aan publicaties ligt voor de hand: hij was een groot dichter. Bovendien bestonden er in de Verenigde Nederlanden tientallen, zo niet honderden uigeverijen die in volle vrijheid boeken konden publiceren. In de Rzeczpospolita was dat absoluut anders.

Morsztyns werken worden in de Poolse literatuurgeschiedenis vandaag 'barok' genoemd. Zijn poëzie was echter, onder invloed van Tasso, Marini en de Franse dichters - maniëristisch. De figura serpentinata, de antithese, het concet- 
tisme: al deze kenmerken zijn in zijn gedichten te vinden. Gedrukt of niet, hij behoort vandaag tot de literaire canon in Polen. Zijn meest bekende gedicht "Do Trupa. Sonet" (Tot een Lijk. Klinkdicht) drukt het maniëristische concetto en de 'icy fire'-antithese op de beste manier uit:

Leżysz zabity i jam też zabity,

Ty - strzałą śmierci, ja - strzałą miłości,

Ty krwie, ja w sobie nie mam rumianości.

Ty jawne świece, ja mam płomień skryty.

Tyś na twarz suknem żałobnym nakryty,

Jam zawarł zmysły w okropnej ciemności,

Ty masz związane ręce, ja wolności

Zbywszy mam rozum łańcuchem powity.

Ty jednak milczysz, a mój język kwili,

Ty nic nie czujesz, ja cierpię ból srodze,

Tyś jak lód, a jam w piekielnej śreżodze.

Ty się rozsypiesz prochem w małej chwili,

Ja się nie mogę, stawszy się żywiołem

Wiecznym mych ogniów, rozsypać popiołem.

$\mathrm{Jij}$ - ligt hier dode; ik - ben ook een dode/

$\mathrm{Jij}$ - door doods pijle, ik - door liefdes pijle/

$\mathrm{Jij}$ - mist bloed, ik - mis wangenrood bij wijle/

$\mathrm{Jij}$ - lichte kaarsen, ik - heb een vlam node/

Jouw aangezicht - onder een doek van rouwe/

Ik sluit mijn zinnen in wreed' donkerheden/

Jouw handen - gebonden. Ik - zonder vrijheden/

En mijn verstand in ketens is gevouwen/

Maar jij - mag zwijgen, en mijn tong moet snikken/

Jij voelt nu niets meer, en ik lijd gedurig/

Jij bent zo ijzig, ik - voel de hel vurig/

Jij wordt tot as, in slechts één ogenblikke/

Ik echter kan niet, zijnde elementen/

Van eeuwige vuren, worden as' fragmenten (vert. SK).

Vondel had dat gedicht niet kunnen lezen: hij kende geen Pools. De Amsterdamse slavist Arent van Nieukerken vraagt (omgekeerd) of Morsztyn wel Vondel had gelezen:

Można mieć uzasadnione wątpliwości, czy kiedykolwiek czytał Lucifera, owo szczytowe osiągnięcie kunsztu dramatycznego największego poety holenderskiego baroku. [Men kan gegronde twijfels hebben of hij ooit Lucifer had gelezen, die topprestatie van de dramatische kunst van de grootste dichter van de Hollandse barok] (Van Nieukerken 1993: 123).

Hij stelt voor, zeer juist, om Morsztyn niet met Vondel te vergelijken, maar met Constantijn Huygens; allebei waren ze diplomaten en allebei waren ze maniëristische dichters (Van Nieukerken 1993: 123). Het was echter niet Jan Andrzej, maar zijn broer Tobiasz die later de hoofdpersoon werd in een van de gedichten 
van Vondel in de bundel De Parnas aen de Belt uit 1657. Die verzameling (met elf kortere en langere gedichten) stelde personages voor die op de een of andere manier met Denemarken en met de Deense zeestraaten van de kleine en grote Belt verbonden waren (de ondertitel luidde Verscheide dichten in Denemerck gedicht). Ook hier, aan de Belt, was, zo Vondel, een mythische Parnassus, de zetel van de muzen. Vondel duidde niet speciaal op de (Poolse) poëzie, maar, algemeen, op de kunsten. De eerste zes gedichten wijdde hij aan de schilderkunst van "Karel van Mander, Hofschilder van zijne Mejesteit Frederick de Derde", (WB VIII, 1935: 611-614); een van die gedichten prees de schilder als auteur van "mijne afbeeldinge" (WB VIII, 1935: 614). De volgende vijf spraken over de heersers van en over diplomaten in Denemarken, want hier bevond zich nu het centrum van de diplomatieke onderhandelingen in de oorlog tegen Zweden. Het woord "Parnas" viel trouwens in de hele bundel (behalve in de titel) maar één keer: in het gedicht voor Koenraet van Beuningen, Godefried van Rheede en Mathias Fiersen, "Gezanten der Hooge Mogende Staeten by de Majesteit te Denemarck". Ik ben, zegt Vondel, door mijn ouderdom nu te traag om die ideale personages te beschrijven: "Hier valt [voor mij] Parnas te steil en spits" (WB VIII, 1935: 620).

"Gezanten": in de ogen van Vondel waren van Beuningen, van Rheede en Fiersen daarom zo belangrijk omdat ze diplomaten waren, in de dienst van de Republiek. Politiek en poëzie samen: in de $17^{\text {de }}$ eeuw was dit niet ongewoon. De Nijmeegse literatuurhistoricus Paul Hulsenboom formuleert het (bij de bespreking van twee Nederlandse missies in 1628 en 1635 en de daarmee verbonden diplomatic poetics) als volgt:

Being a diplomat in early modern Europe often involved being a poet as well. Hence a poet could just as easily become a part-time diplomat: both could use the tool of poetry in diplomatic practice. Poets not only commented on the political situation, therefore. Instead, they were part of it, actively shaping public opinions and international relations - in various languages (Hulsenboom 2019: 101).

En dan komt in De Parnas aen de Belt, als laatste, het gedicht "Aen zijn Excellentie, den doorluchtigen Heere, Tobias Morstin, Trucksesz te Krakou, Resident van den Koning en de Kroon van Polen by de Koning Frederick den Derden".

Truchsess Morsztyn (Pools: stolnik, in die tijd te vergelijken met de Nederlandse drost) had volgens Vondel eveneens een belangrijke rol gespeeld als diplomaat. $\mathrm{Nu}$ als gezant van Johan Casimir in Kopenhagen, en eerder aan het begin van de 'Zweedse Zondvloed' aan het hof van de Poolse koning, in de herfst 1655, was hij een zeer belangrijke persoon. Hij was degene die "Het Heilighdom des Rijx", de Poolse regalia, in het Wawelkasteel in Kraków uit de handen van de Zweedse vijand had gered,

En voert dien koninglijcken schat,

Zes kroonen, scepters, en gewaeden, 
Door 's vyants heir, door vloet en vier,

En berght de heilige cieraden,

Ten prijs van Gode en Kazimir,

Voor's haeters vloeck en klaeuwen veiligh [...] (WB VIII, 1935: 623).

Tobiasz was dus een held. Zo stelde Vondel dat voor; of: zo had Tobiasz het hem persoonlijk verteld. Zij ontmoetten elkaar in 1657 in Kopenhagen, toen Vondel zijn (tweede) reis daarnaartoe ondernam om zijn financiële situatie te regelen, en waar Tobiasz als gezant van de Poolse koning op het hof van Frederik III voor de Poolse belangen in de oorlog tegen Zweden optrad (zie over de context van die ontmoeting in Kopenhagen Van Nieukerken 2002: 139-142).

Vondel beschreef poëtisch de heldendaden van Tobiasz; hij zei dat de Pool de "getrouwste hofstijl der Sarmaten" was:

Getrouwste hofstijl der Sarmaeten,

$\mathrm{Na}$ zoo veel onrechts berghde ghy

Te Warssou 't lijf van dien verwaten

Erfvyant, hielt uw sabel vry

Van wederwracke en bloetvergieten,

En streckte uw' Vorst een rechte hant,

Schoon duizenden de Kroon verlieten [...] (WB VIII, 1935: 623).

Tobiasz Morsztyn was dus de steunpilaar aan het hof van de Poolse koning: op hem kon deze altijd rekenen. Of die formulering overdreven was, hoe het in de werkelijkheid was, is een andere kwestie, maar hier speelde (nog eens de woorden van Hulsenboom) de poëtische diplomatie een belangrijke rol.

Meteen na deze lofprijzing krijgt Tobiasz er nóg een van Vondel, en nu in samenhang met zijn broer Jan Andrzej:

$\mathrm{Nu}$ voert uw wijsheit, als Gezant

Van 't Rijck, het woort te Koopenhaven,

Gelijck uw broeder binnen Praegh,

Op wiens trompet mijn dichten draven,

Zo verre Apollo dit behaegh (WB VIII, 1935: 623-624).

Tobiasz was dus een wijze gezant van de Poolse Kroon in Denemarken; zijn broer was ook een gezant. De naam van Jan Andrzej valt hier niet, maar hij was het die door Vondel bedoeld werd; hij verbleef in die tijd inderdaad als gezant van de Poolse koning in de hoofdstad van Bohemen. Het lijkt alsof Vondel in hem een dichter zag (zo Van Nieukerken 2002: 141), maar dat was niet zo. Zijn "trompet" was geen verwijzing naar diens poëzie. Het was wel de fanfare van zijn zegeviering in zijn (echte of vermeende) succesvolle activiteiten als diplomaat.

Hij kon weliswaar over de poëtische ativiteiten van Jan Andrzej Morsztyn gehoord hebben via broer Tobiasz, maar hij had ze zeker onmogelijk in het origineel kunnen lezen (zo ook Van Nieukerken 2002: 140). Ze waren, zoals bekend, 
toen niet gedrukt en lagen alleen in handschriften voor. Die had Vondel misschien wel bij Tobiasz gezien; maar, nog eens, hij kende geen Pools en kon ze niet lezen.

Vondel en de Morsztyns konden wel met elkaar over Holland spreken; zoals reeds geschreven, studeerden de Polen twintig jaar eerder in Leiden. Maar elkaars poëzie kennen? Dat moest wel een éénrichtingsverkeer zijn: de broeders Morsztyn hadden daar wel over de werken van Vondel gehoord, misschien ook het eerste moderne theater op het Europese continent, de Amsterdamsche Schouwburg, gezien, met treurspelen van Vondel. Andersom lijkt dat echter niet zo te zijn. Arent van Nieukerken spreekt over een "circumstantial evidence" van Vondels grote interesse voor Morsztyn (Van Nieukerken 2002: 140). Het lijkt eenvoudiger: de werken van Vondel (en uiteraard van zo veel andere dichters) waren vervuld met gelegenheidspoëzie over zo vele toen belangrijke personages, en in dit geval over Morsztyn.

Vondel had hier, net als in zijn andere 'Poolse' gedichten, altijd één motief voor ogen: De 'Moedernegotie'. Hij schreef, tot slot van zijn gedicht, direct nadat hij de "boeder binnen Praegh" noemde, de volgende woorden over Tobiasz:

Gy zult de groote korenschuuren

Van Christenrijck door vasten pais

Verdaedigen, de nagebuuren

In Koning Federicks palais

Vereenigen naer uw vermogen:

Dan zal mijn keel, op zang gestelt,

Uw dapperheên aen 's hemels boogen

Verheffen, langs de blijde Belt,

Waer langs de Wijssel uitgegooten

Ons toestroomt met gelade vlooten (WB VIII, 1935: 624).

\section{Conclusie}

De Republiek der Zeven Verenigde Nederlanden en de Republiek der Twee Naties hadden in de $17^{\text {de }}$ eeuw heel veel contacten met elkaar, zeer "intensieve betrekkingen" op het gebied van handel, politiek en religie (Van Nieukerken 2002: 127). De Poolse poëzie vormt hier echter "een witte vlek"; en Vondels gedicht voor Tobiasz Morsztyn is slechts "een incidentele aanwezigheid", "niet meer dan een literaire curiositeit" (Van Nieukerken 2002: 144).

Maar het was geen curiositeit; het was een van de zo vele voorbeelden in de toenmalige literaire wereld. Zoals gezegd, schreven Vondel en andere dichters vaak gelegenheidsgedichten. De Parnas aen de Belt is er een voorbeeld van. En Morsztyn, Tobiasz Morsztyn, is hier wel een belangrijk personage.

Dit laat ook, nogmaals, het perspectief van Vondel bevestigen: het is wel een belangrijke figuur, maar alleen in een concrete context. In de lovende bewoor- 
dingen van Vondel over Morsztyn is een dubbele bodem te ontdekken. Het perspectief van de broeders Morsztyn was vooral naar Frankrijk gericht, en, zoals we zagen, zelfs tegen de Poolse koning. Vondels perspectief was níet naar Polen als een politieke mogendheid gericht, maar naar de Nederlandse 'Moedernegotie' in de Oostzee, tussen de Sont en Dantzig. Een (door oorlog) 'gesloten' Sont maakte de graanhandel met Polen onmogelijk. Vondel lette op de interesses van de Republiek. En dat was dan niet de Republiek der Twee Naties...

Eerder in deze tekst werd gezegd dat Polen in politiek opzicht een belangrijke rol in Europa speelde, maar in cultureel opzicht een veel minder belangrijke. Er was één grote uitzondering: de reeds eerder genoemde dichter-jezuiet Maciej Kazimierz Sarbiewski. Hij was in zijn tijd beroemd in heel Europa, ook in de Nederlanden; in tegenstelling tot Morsztyn, Jan Andrzej Morsztyn.

Maar één keer trad hij, enigszins in de schaduw van zijn broer Tobiasz, tevoorschijn, toen Vondel over Tobiasz als over de "getrouwste hofstijl der Sarmaeten" sprak, en ook zijn broeder, de "wijze gezant binnen Praegh" (Jan Andrzej dus) noemde. Uiteraard dacht Vondel hier in de eerste plaats aan de "Moedernegotie', maar hij gebruikte daarvoor de "public diplomacy" (Hulsenboom 2019: 74): de poëzie voor de politiek.

\section{Bibliografie}

Bachiene, Willem Albert (1793): Beknopte beschryving nevens eene naauwkeurige afgezette kaart der Zeven Vereenigde Nederlanden. Amsterdam: Dirk onder de Linden en zoon, laatst geraadpleegd op 14.05.2020<https://www.dbnl.org/tekst/bach005bekn01_01/bach005bekn01_01_ 0003.php>.

Borowski, Andrzej (2007): Iter Polono-Belgo-Ollandicum. Cultural and Literary Relationships between the Commonwealth of Poland and the Netherlands in the 16th and 17th Centuries. Kraków: Księgarnia Akademicka.

Colenbrander, Herman Theodoor (1925): "De herkomst der Leidsche studenten". Pallas Leidensis $M C M X X V, 275-303$.

Court, Pieter de la (1662): Interest van Holland, ofte gronden van Hollands-Welvaren. Amsterdam: Joan Cyprianus vander Gracht, laatst geraadpleegd op 14.05.2020<https://www.dbnl.org/ tekst/cour001inte01_01/cour001inte01_01_0011.php>.

Goes, Joannes Antonides (1671): De Ystroom. Āmsterdam: Pieter Arentsz, laatst geraadpleegd op 14.05.2020 <https://www.dbnl.org/tekst/anto001ystr01_01/anto001ystr01_01_0015.php>.

Hernas, Czesław (1999): Barok. Warszawa: Wydawnictwo Naukowe PWN.

Hulsenboom, Paul (2019): "Diplomats as poets, poets as diplomats. Poetic gifts and literary reflections on the Dutch mediations between Poland-Lithuania and Sweden in the first half of the seventeenth century". Legatio. The Journal for Renaissance and Early Modern Diplomatic Studies 3, 63-110.

Israel, Jonathan (1995): The Dutch Republic: Its Rise, Greatness, and Fall, 1477-1806. Oxford/New York: Oxford University Press.

Jasienica, Paweł (2018): Rzeczpospolita Obojga Narodów. Srebrny Wiek. Warszawa: Prószyński i S-ka.

Neerlandica Wratislaviensia 30, 2020

(C) for this edition by CNS 
Karpiński, Adam, \& Adam Stepnowski (ed.) (1999): Pierre Corneille, Jan Andrzej Morsztyn, Cyd albo Roderyk. Warszawa: Instytut Badań Literackich.

Kiedroń, Stefan (1992): "Poolse studenten in Leiden in de $16^{\mathrm{e}}$ en $17^{\mathrm{e}}$ eeuw". In: Stanisław Prędota (ed.), Studia Germanica et Neerlandica. Wrocław: Wydawnictwo Uniwersytetu Wrocławskiego, 189-204.

Kuiper Jr., Abraham (1899): Johannes Maccovius. Leiden: D. Donner.

Mandere, H.CH.G.J. van der (1920): "Het Poolsche vraagstuk in het midden der zeventiende eeuw". De Nieuwe Gids 35, 374-384, laatst geraadpleegd op 11.06.2020<https://www.dbnl.org/tekst/ nie002192001_01/_nie002192001_01_0042.php>.

Nieukerken, Arent van (1993): "Polonica w dwóch wierszach Vondela". Pamiętnik Literacki 84:2, $119-125$.

Nieukerken, Arent van (2002): “Vondels 'Parnas aen de Belt' en de gebroeders Morsztyn". AMOS VI. 170 jaar neerlandistiek in Silezië (= Acta Comenii Societatis Neerlandicorum Europae Centralis Et Orientalis), 127-144.

Norkus, Zenonas (2017): An Unproclaimed Empire: The Grand Duchy of Lithuania: From the Viewpoint of Comparative Historical Sociology of Empires. New York: Routledge.

Odlozilik, Otakar (1963): "Rembrandt's Polish Nobleman". The Polish Review 8:4, 3-32.

Otterspeer, Willem (2000): Groepsportret met Dame. Het bolwerk van de vrijheid. De Leidse universiteit 1575-1672. Amsterdam: Uitgeverij Bert Bakker.

Porteman, Karel, \& Mieke B. Smits-Veldt (2008): Een nieuw vaderland voor de muzen. Geschiedenis van de Nederlandse literatuur 1560-1700. Amsterdam: Uitgeverij Bert Bakker.

Rieu, W. de (ed.) (1875): Album Studiosorum Academiae Lugduno-Batavae 1575-1875. 's-Gravenhage: Apud Martinum Nijhoff.

Schama, Simon (1987): The Embarrassement of Richies. An Interpretation of Dutch Culture in the Golden Age. New York: Alfred A. Knopf.

Schama, Simon (1989): Overvloed en Onbehagen. De Nederlandse Cultuur in de Gouden Eeuw. Amsterdam: Atlas Contact.

Sterck, J.F.M., e.a. (ed.) (1929): De werken van Vondel. Derde deel 1627-1640. Amsterdam: De Maatschappij voor goede en goedkope lectuur (= WB III).

Sterck, J.F.M., e.a. (ed.) (1931): De werken van Vondel. Vijfde deel 1645-1656. Amsterdam: De Maatschappij voor goede en goedkope lectuur (= WB V).

Sterck, J.F.M., e.a. (ed.) (1935): De werken van Vondel. Achtste deel 1656-1660. Amsterdam: De Maatschappij voor goede en goedkope lectuur (= WB VIII).

Stone, Daniel (2014): The Polish-Lithuanian State, 1386-1795. Washington: University of Washington Press.

Tazbir, Janusz (1973): A country without stakes: Polish religious toleration in the sixteenth and seventeenth centuries. New York: The Kościuszko Foundation, Twayne Publishers, Państwowy Instytut Wydawniczy.

Tazbir, Janusz (1974): “Makowski (Maccovius) Jan”. Polski Stownik Biograficzny XIX, 240-241.

Vos, Louis, \& Idesbald Goddeeris (2005): De strijd van de witte adelaar. Geschiedenis van Polen (966-2004). Leuven/Voorburg: Acco.

Wansink, H. (1981): Politieke wetenschappen aan de Leidse Universiteit 1575- \pm 1650 . Utrecht: Hes Publishers.

Wilczek, Piotr (2016): Polonia Reformata. Essays on the Polish Reformation(s). Göttingen: Vandenhoeck \& Ruprecht.

Neerlandica Wratislaviensia 30, 2020

(C) for this edition by CNS 